\title{
Gel Emulsions as Controlled Drug Delivery Systems
}

\author{
M. BUDAI-SZÜCS, I. ERŐS \\ Department of Pharmaceutical Technology, University of Szeged, H-6720 Szeged \\ E-mail: eros@pharm.u-szeged.hu (E. Eros) \\ Sci Pharm. 2010; 78: 598 \\ doi:10.3797/scipharm.cespt.8.PDD09
}

Gel emulsions represent special drug delivery systems. Up to present only some authors dealt with the formation and properties of these systems, although the gel emulsions assurance interesting and useful possibility as controlled drug delivers systems [1-4]. Several methods can be applied by their preparations: i) gelling of internal water phase with hydrophilic polymers, ii) gelling of oil-phase with hydrophobic colloids, iii) in situ polymerisation, iv) application of gel emulsifying agents. Their advantages are as follows: i) prominent mucoadhesion, ii) capable of floating on the gastric fluid $[2,3,5]$.

In our experiments water-soluble (polar) and water-insoluble (unpolar) active agents were applied. Composition of gel emulsions, e. g. the ratio of water- and oil phase, the concentration of surface active copolymers, addition of coemulsifiers was changed systematically.

The drug release from emulsions was investigated by Hanson SR8 plus equipment and Franz vertical diffusion cell. The rheological characteristics was measured by Paar Physica oscillation rheometer Optical studies were accomplished with Leica image analyzer, and thermal-analytic investigations were carried out with DSC 281. Mettler Toledo equipment.

Relationships were established between following parameters: i) drug release vs. mucoadhesion, ii) concentration of polymer emulsifying agents vs. drug release iii) presence of microgel layer surrounding oil droplets vs drug release, iv) concentration of oil phase vs drug release.

[1] Marquardt D, Sucker $\mathrm{H}$. Oil-in water-emulsion gels: determination and mathematical treatment of flow properties. Eur J Pharm Biopharm. 1998; 46: 115-124. doi:10.1016/S0939-6411(97)00167-7

[2] Lian G, Malone ME, Homan JE, Norton IT. A mathematical model of volatile release in mouth from the dispersion of gelled emulsion particles. J Control Release. 2004; 98: 139-155. doi:10.1016/j.jconrel.2004.04.017

[3] Sriamornsak P, Thirawong N, Puttipipatkhachorn S. Emulsion gel beads of calcium pectinate capable of floating on the gastric fluid: effect of some additives, hardening agent or coating on release behavior of metronidazole. Eur J Pharm Sci. 2005; 24: 363-373. doi:10.1016/j.ejps.2004.12.004

[4] Murdan S, Andrýsek T, Son D. Novel gels and their dispersions--oral drug delivery systems for ciclosporin. Int J Pharm. 2005; 300: 113-124. doi:10.1016/j.ijpharm.2005.06.002

[5] Szucs M, Sandri G, Bonferoni MC, Caramella CM, Vaghi P, Szabó-Révész P, Eros I. Mucoadhesive behaviour of emulsions containing polymeric emulsifier. Eur J Pharm Sci. 2008; 34: 226-235. doi:10.1016/j.ejps.2008.03.005 